ИЗВЕСТИЯ АКАДЕМИИ НАУК ЭСТОНСКОП ССР. ТОМ 30 ФИЗИКА * МАТЕМАТИКА, 1981, № 1

\title{
M. KAGANOVITS
}

\section{APPROXIMATE EFFECTIVE DESIGN AND SLIDING PLANNING}

\author{
(Presented by N. Alumäe)
}

1. A problem of consistent planning, being discussed in the recent literature on the theory of economic growth, arises when there is no perfect foresight of future technologies and goals, and so infinite-horizon optimal programs are impossible to compute. Let a perspective plan be determined as a finite program maximizing some terminal objective function under technological restrictions, initial stocks and length of planning period being fixed. It is clear that plans of the last years of planning period essentially depend on the objective function and therefore may, in general, be non-optimal from the point of view of further development, i. e. inconsistent with plans for subsequent periods.

From practice of perspective planning the concept of yearly revision of plans is known - the so-called sliding planning. In a sliding plan, the optimal program is computed anew at the end of every year (or longer period), an additional year being appended to the last, the planning horizon thus remaining constant. Asymptotic properties of the sliding planning procedure have been studied with the help of mathematical models in $\left[{ }^{1-5}\right]$. In $\left[{ }^{1,2,4,5}\right]$, several-kinds of models with constant technologies are considered, and it is shown that a sliding plan (i.e. the path provided by the procedure) approaches or converges to the turnpike. In $\left[{ }^{3}\right]$, the technologies in a model of temporary equilibrium are allowed to vary, but within uniform bounds. The sliding plan is shown to lie close to the infinite effective equilibrium path.

Here, a model of von Neumann-Gale type is considered. The technologies are supposed to be known for $T$ years in advance, at the end of every year an information of a subsequent year is got, so that the planning horizon remains always equal $T$ years. Under some uniform concavity conditions imposed on the technological sets, optimal programs prove to depend little, at the beginning of planning period, on the objective function and a distant future*. Thereby, the sliding plan, being 'sewn' of the initial steps of optimal programs, approximates the infinite optimal (or effective) program, which could be post factum defined, when all the technologies would be known. For this reason, the procedure of sliding planning may be called an approximate design of infinite effective program and treated as an approximately consistent iterative planning procedure.

Definitions and the basic result (Theorem 1) are formulated in section 2; in section 3, auxiliary definitions and statements (without

* Analogous facts were stated in $\left[{ }^{6}\right]$ for a different model. 
proofs) are given; in section 4 , a frame of the proof of Theorem 1 is provided.

Notation. $R_{+}^{n}$ is a non-negative orthant of $R^{n} ; x^{(i)}$ stands for $i$-th coordinate of $x ; x \geqslant y$ means $x^{(i)} \geqslant y^{(i)}, i=1, \ldots, n ; x>y \Rightarrow x^{(i)}>y^{(i)}$, $i=1, \ldots, n ;\|x\|=\sum_{i=1}^{n}\left|x^{(i)}\right| ;$ angular distance $\mathrm{\varrho}(x, y)=\|x /\| x\|-y /\| y\|\|$; $x y=\sum_{i=1}^{n} x^{(i)} y^{(i)} ;(x, y)$ denotes a $2 n$-dimensional vector with first $n$ coordinates composing vector $x$ and the last $-y$. Linear functionals in $R^{n}$ are treated as vectors.

2. Let the technology be described by a sequence of sets $Z_{t} \subset R_{+}^{n} \times R_{+}^{n}$ corresponding to discrete time periods $t=0,1, \ldots . Z_{t}$ is interpreted as a set of all input-output pairs $(x, y)$ technologically possible at a period $t$. Definition 1 . A sequence $\left\{x_{t}\right\}_{t=\tau}^{\tau+T}$, where $\tau=0,1, \ldots, 1 \leqslant T \leqslant+\infty$, $x_{\tau}=x \geqslant 0$, is a $[x, \tau, T]$-feasible program if $\left(x_{t}, x_{t+1}\right) \in Z_{t}, t=\tau, \ldots, \tau+$ $+T-1$.

According to this definition, we shall say for simplicity's sake that a program starts at a moment $\tau$ from a point $x$ and attains a point $x_{\tau+T}$.

In general, an $[x, \tau, T]$-feasible program is not unique.

Definition 2. An $[x, \tau, T]$-feasible program $\left\{x_{t}\right\}$ with a finite horizon $T$ is called effective if there is no such $[x, \tau, T]$-feasible program $\left\{y_{t}\right\}$ that $y_{\tau+T}>x_{\tau+T}{ }^{* *}$. An infinite-horizon $[x, \tau, \infty]$-feasible program $\left\{x_{t}\right\}_{t=\tau}^{\infty}$ is effective if its every finite piece $\left\{x_{t}\right\}_{t=\tau}^{\tau+T}, T=1,2, \ldots$, is effective.

Let the following assumptions on technological sets be valid for all $t=0,1, \ldots$.

A.1. $Z_{t}$ is closed convex cone.

A.2. $(0, y) \in Z_{t} \Leftrightarrow y=0$ (nothing can be produced from nothing).

A.3. $(x, y) \in Z_{t}, z \leqslant y \Rightarrow(x, z) \in Z_{t}-$ a free disposal.

It should be noted that by A.1 and A.3 the following implication is also true

$$
(x, y) \in Z_{t}, \quad z \geqslant x \Rightarrow(z, y) \in Z_{t} .
$$

In $\left[{ }^{8}\right]$, it is proved that under the assumptions made, there exists an equilibrium system $\sigma=(\bar{\chi}, \varphi, \alpha)$, where $\bar{\chi}=\left\{\bar{x}_{t}\right\}_{t=0}^{\infty}$ is a feasible program; $\varphi=\left\{f_{t}\right\}_{t=0}^{\infty}-$ a sequence of equilibrium prices - linear functionals $f_{t} \geqslant$ $\geqslant 0,\left\|f_{t}\right\|=1, t=0,1, \ldots ; \alpha=\left\{\alpha_{t}\right\}_{t=0}^{\infty}-$ a sequence of positive numbers such that $f_{a} \bar{x}_{0}>0$ and for $t=0,1, \ldots$ hold

$$
\begin{gathered}
f_{t+1} y \leqslant \alpha_{t} f_{t} x, \quad \forall(x, y) \in Z_{t}, \\
f_{t+1} \bar{x}_{t+1}=\alpha_{t} f_{t} \bar{x}_{t} .
\end{gathered}
$$

Note that a system $(b \bar{\chi}, \varphi, \alpha)$, where $b \bar{\chi}=\left\{b \bar{x}_{t}\right\}_{t=0}^{\infty}$ is equilibrium for any positive scalar $b$. Thereby, without loss of generality, we can consider that $f_{0} \bar{x}_{0}=1$.

** Note that this definition of effectiveness is slightly more general, than the traditional one - see e. g. [ $\left.{ }^{7}\right]$. 
We make the following fundamental assumption which may be called a uniformly strict convexity of technologies by inputs ${ }^{* * *}$ :

A.4. For any $\varepsilon>0$ there exists such $\delta(\varepsilon)>0$ that for every $t$ the conditions $(x, y) \in Z_{t},\left(x^{\prime}, y^{\prime}\right) \in Z_{t}, \mathrm{Q}\left(x, x^{\prime}\right) \geqslant \varepsilon$ imply

$$
\left(\left(x+x^{\prime}\right) / 2-v,\left(y+y^{\prime}\right) / 2\right) \in Z_{t},
$$

for any vector $v \geqslant 0$ satisfying the inequality $\|v\| \leqslant \delta(\varepsilon)\left(\|x\|+\left\|x^{\prime}\right\|\right) / 2$.

From this assumption it can be easily derived that the system $\sigma$ is uniformly strict equilibrium:

$$
f_{t+1} y \leqslant \alpha_{t}(1-\delta(\varepsilon)) f_{t} x
$$

where $(x, y) \in Z_{t}, \mathrm{\varrho}\left(x, \bar{x}_{t}\right) \geqslant \varepsilon, t=0,1, \ldots$.

One more important assumption is supposed to hold:

A.5. $\inf _{t \geqslant 0} \min _{1 \leqslant i \leqslant n} \bar{x}_{t}^{(i)} /\left\|\bar{x}_{t}\right\|=c>0$.

From here on, A.1 - A.5 are assumed to be valid.

Lemma 1. For any feasible program $\chi=\left\{y_{t}\right\}_{t=\tau}^{\infty}$ there exists such scalar $\lambda=\lambda(\chi) \geqslant 0$ that

$$
\prod_{s=\tau}^{t-1} \alpha_{s}^{-1}\left(y_{t}-\lambda \bar{x}_{t}\right) \underset{t \rightarrow \infty}{\longrightarrow} 0 .
$$

A program $\chi$ will be said to grow at the rate of $\alpha$ if $\lambda(\chi)>0$.

A final assumption concerns the vector $x_{0}$ of initial stocks:

A.6. There exists a program starting from $x_{0}$ at a moment $t=0$ and growing at the rate of $\boldsymbol{\alpha}$.

Now, the basic notion and result of the paper can be formulated.

Definition 3. A sequence $\{x(t)\}_{t=0}^{\infty}$ is called sliding plan with horizon $T<+\infty$ if for every $t=0,1, \ldots$ there exists an $[x(t), t, T]$-effective program $\left\{y_{s}(t)\right\}_{s=t}^{t+T}$ such that $y_{t+1}(t)=x(t+1)$. Here $x(0)=y_{0}(0)$ is $a$ vector of initial stocks, $y_{s}(t)$ - an output plan accounted at a period $t$ for $s$ years forward.

Let $\left\{x_{t}\right\}_{t=0}^{\infty}$ be $\left[x_{0}, 0, \infty\right]$-effective program. In view of A.4 it is unique.

Theorem 1. Under assumptions A.1 - A.6, for any $\varepsilon>0$ there exists such integer $T(\varepsilon)$ that for any sliding plan $\{x(t)\}_{t=0}^{\infty}$ with initial stocks $x(0)=x_{0}$ and horizon $T \geqslant T(\varepsilon)$

$$
\mathrm{Q}\left(x(t), x_{t}\right)<\varepsilon, \quad t=0,1, \ldots .
$$

3. A frame of the proof of Theorem 1 is principally similar to the one used in [4]. As well as there, a notion of effective functional proposed by A. Rubinov $\left[{ }^{10}\right]$ is used. Although it has been introduced for constant technology, the following natural generalization for the case of varying ones can be made:

Definition 4. A sequence of functionals $q_{t}: R_{+}^{n} \rightarrow R_{+}, t=0,1, \ldots$ is called effective, and, respectively, every functional $q_{t}$ of this sequence is

\footnotetext{
*** An analogous assumption has been made in $\left[{ }^{9}\right]$. If the technologies are determined in terms of Cobb-Duglas production functions, then A.4 is valid if the elasticities of all goods are uniformly bounded from zero in all periods.
} 
called effective if $q_{t}$ are superlinear (i.e. linearly homogeneous and concave), continuous, monotone $\left(q_{t}(x)>q_{t}(y)\right.$ if $\left.x>y\right)$, and

$$
\alpha_{t} q_{t}(x)=\max \left\{q_{t+1}(y) \mid(x, y) \in Z_{t}\right\} .
$$

Theorem 2. Effective sequences of functionals $\left\{q_{t}\right\}_{t=0}^{\infty}$ exist.

The proof proceeds as follows. Functionals $q_{t}$ are defined in a special way $\left(q_{t}(x)=\max \{\lambda(\chi) \mid \chi \in P(x, t)\}\right.$, where $P(x, t)$ is a set of all $[x, t, \infty]$-programs, $\lambda(\chi)$ is a value given in Lemma 1), and all the required properties of them are proved analogously to [ $\left.{ }^{10}\right]$.

For a fixed arbitrary $\gamma>0$ consider a compact set $K=\{x \geqslant 0 \mid\|x\|=1$, $\left.x^{(i)} \geqslant \gamma, i=1, \ldots, n\right\} \quad$ (i. e. a set strictly interior for unit simplex) and denote $\bar{K}=\operatorname{con} K$ its conic hull in $R_{+}^{n}$ with vertex in zero. It can be easily seen that $x \in \bar{K}$ if $\varrho\left(x, \bar{x}_{t}\right)<c-\gamma$.

Lemma 2. Functionals of the effective sequence $\left\{q_{t}\right\}_{t=0}^{\infty}$ are equicontinuous on $\bar{K}$, i.e. for $\forall \delta>0 \exists \varepsilon_{1}>0:$ for $\forall x, y \in K$, inequality $\|x-y\|<\varepsilon_{1}$ implies that $\left|q_{t}(x)-q_{t}(y)\right|<\delta$ for all $t=0,1, \ldots$.

Proof of the Theorem 1 is mainly based on the strong turnpike theorem, but for technical reasons its more general (a somewhat uniform) statement than the original one $\left[{ }^{11}\right]$ is needed here.

Fix an arbitrary $\beta>0$. Denote $K_{\beta, \tau}=\left\{x \geqslant 0 \mid\|x\|=1, q_{\tau}(x) \geqslant \beta\right\}$, and define $\bar{K}_{\beta, \tau}=$ con $K_{\beta, \tau}-$ its conic hull in $R_{+}^{n}$ with a vertex in zero.

The orem 3. For $\forall \varepsilon>0 \exists$ such integer $N_{0}(\varepsilon)$ that for all $[x, \tau, T]$-effective programs $\left\{x_{t}\right\}$, where $2 N_{0}(\varepsilon) \leqslant T \leqslant+\infty, x \in \bar{K}_{\beta, \tau}, \tau=0,1, \ldots$,

$$
\mathrm{Q}\left(x_{t}, \bar{x}_{t}\right)<\varepsilon,
$$

for $t=\tau+N_{0}(\varepsilon), \ldots, \tau+T-N_{0}(\varepsilon)$.

Comment. Present statement of the theorem is stronger than the one in [ $\left.{ }^{11}\right]$ in two respects:

1. The estimate $N_{0}(\varepsilon)$ is uniform for all $x \in \bar{K}_{\beta, \tau}, \tau=0,1, \ldots$.

2. Some technical conditions are eliminated, namely, a restriction on the objective functional (in [11] such positive constants $k$ and $K$ are required to exist that $k f_{\tau+T} \leqslant f \leqslant K f_{\tau+T}$, where $f$ is the objective functional, in terms of which terminal stocks are maximized) as well as a condition that a sequence $\varphi=\left\{f_{t}\right\}_{t=0}^{\infty}$ of equilibrium prices is strictly bounded from zero by all coordinates. In fact, the latter condition can be derived from the rest of assumptions:

Lemm a 3. $\inf _{t \geqslant 0} \min _{1 \leqslant i \leqslant n} f_{t}^{(i)}=m>0$.

4. An auxiliary notion is needed in what follows:

Definition 5. A feasible program $\left\{x_{t}^{*}\right\}_{t=\tau}^{\infty}$ is a path of effective design if

$$
q_{t+1}\left(x_{t+1}^{*}\right)=\max \left\{q_{t+1}(y) \mid\left(x_{t}^{*}, y\right) \in Z_{t}\right\}=\alpha_{t} q_{t}\left(x_{t}^{*}\right),
$$

for all $t \geqslant \tau, \tau=0,1, \ldots$.

This path is evidently a $\left[x_{\tau}^{*}, \tau, \infty\right]$-effective, which is in our case unique. Hence maximizing at every step of current effective functional provides a design of effective program. 
Frame of the proof of Theorem 1. Throughout here, we consider without loss of generality $\alpha_{t}=1, t=0,1, \ldots$.

Step 0 . Take an arbitrarily small $\varepsilon>0$. Let $c$ and $m$ be constants from A.5 and Lemma 3, $\delta(\cdot)$ and $N_{0}(\cdot)$ - values given in A.4 and Theorem 3, respectively.

Choose $\gamma=c / 2$ (see the definition of the set $K$ in Lemma 2), $\beta=$ $=\min \left\{q_{0}\left(x_{\theta}\right) m / 2\left\|x_{\theta}\right\|, \quad m / 2\right\}, \quad \delta=\min \left\{\delta(\varepsilon / 2) q_{0}\left(x_{0}\right) m / 3\left\|x_{0}\right\|, \quad q_{0}\left(x_{0}\right) / 2\left\|x_{0}\right\|\right\}$, $N=N_{\theta}(\varepsilon / 2)$.

Assign $\tau=0$.

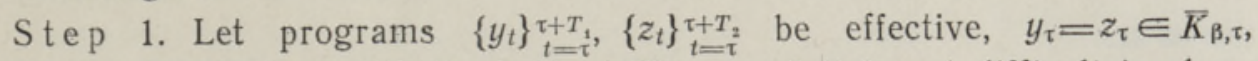
$T_{1}, T_{2} \leqslant+\infty$. Then with the help of Theorem 3 it is not difficult to show that for any $\varepsilon_{1}>0$ there exists such integer $T_{0}\left(\varepsilon_{1}\right)$ that if $T=\min \left\{T_{1}, T_{2}\right\} \geqslant$ $\geqslant 2 T_{0}\left(\varepsilon_{1}\right)$, then

$$
\left\|y_{t}-z_{t}\right\| \leqslant \varepsilon_{1}\left\|y_{\tau}\right\|, t=\tau+T_{0}\left(\varepsilon_{1}\right), \ldots, \tau+T-T_{0}\left(\varepsilon_{1}\right) .
$$

Step 2. Let the path $\left\{z_{t}\right\}$ in Step 1 be a path of effective design, then from Step 1, A.5, Lemma 2 and (7) it follows that there exists such integer $T_{1}(\delta)$ that for any effective path $\left\{y_{t}\right\}_{t=\tau}^{\tau+T}$, with $y_{\tau} \in \bar{K}_{\beta, \tau}, T \geqslant$ $\geqslant 2 T_{1}(\delta)$,

$$
0 \leqslant q_{t}\left(y_{t}\right)-q_{t+1}\left(y_{t+1}\right) \leqslant \delta\left\|y_{\tau}\right\|, t=\tau, \ldots, T-T_{1}(\delta)-1 .
$$

Step 3 . Let the sliding planning horizon satisfy $T \geqslant 2 T_{1}(m \delta / 2 N)$. Then, applying Step 2, it can be seen that

$$
0 \leqslant q_{\tau+t-1}(x(\tau+t-1))-q_{\tau+t}(x(\tau+t)) \leqslant \delta\|x(\tau)\| / 2 N,
$$

$t=1, \ldots, 2 N$, taking into account, that by choice of $\delta$ and $\beta$, for every $t=1, \ldots, 2 N$ holds $x(t) \in \bar{K}_{\beta, \tau}$. Thus,

$$
0 \leqslant q_{\tau}(x(\tau))-q_{\tau+t}(x(\tau+t)) \leqslant \delta\|x(\tau)\|, t=1, \ldots, 2 N .
$$

Step 4. Combining (12) with the strict concavity assumption A.4 and the choice of $\delta$, implies $Q\left(x(\tau+t), x_{\tau+t}^{*}(\tau)\right)<\varepsilon / 2, t=0, \ldots, 2 N$, where $\left\{x_{\tau+t}^{*}(\tau)\right\}$ denotes a path of effective design, starting from a point $x(\tau)$ at a moment $\tau$. In order to prove the desired (6) for $t=N, \ldots, 2 N$ it remains, by the choice of $N$, to apply Theorem 3 to programs $\left\{x_{t}\right\}$ and $\left\{x_{\tau+t}^{*}(\tau)\right\}$, and use the triangle inequality (note that if $\tau=0$, (6) then automatically holds also for $t=0, \ldots, N-1$ ).

Step 5. From the last conclusion it follows, in particular, that $x(\tau+-N) \in$ $\in \bar{K}_{\beta, \tau+N}$. Thereby, reassigning $\tau=\tau+N$ and applying Steps $1-4$, (6) can be proved for subsequent $N$ periods. Proceeding further in this way, it is carried out for any integer $t$. The proof is thus completed.

\section{R EF E R E C E S}

1. Goldm a n, S., Rev. Econ. Stud., 35, № 2, 145-154 (1968).

2. Берез нев а Т. Д., Экономика и матем. методы, 12, № 4, 740-746 (1976).

3. Полтерович В. М., Экономика и матем. методы, 15, № 4, $760-773$ (1979).

4. К аг н о и ч М., Изв. АН ЭССР, Физ. Матем., 28, № 4, 310-316 (1979).

5. К а г н о и ч М., Изв. АН ЭССР, Физ. Матем., 29, № 2, $145-149$ (1980).

6. Nermuth, M., J. Math. Econ., 5, № 3, 289-301 (1978).

7. Nikaido, H., Convex Structures and Economic Theory, Academic Press, New York, 1968.

8. Рубинов А. М., В кн.: Оптимальное планирование, вып. 9, Новосибирск, «Наука», 1967, с. $87-111$. 
9. Полтерович В. М., В кн.: Методы функционального анализа в матсматической экономике, М., «Наука», 1978 , с. $56-97$.

10 Р уби нов А. М., В кн.: Оптимизация, вып. 17(34), Новосибирск, «Наука», 1975, c. $40-45$

11. Р уб ин ов А. М., Ш а п и ев К. Ш., В кн.: Оптимальное планирование, вып. 10 , Новосибирск, «Наука», 1968, с. 15-27.

Academy of Sciences of the Estonian SSR,

Received Institute of Cybernetics

\section{KAGANOVITS}

\section{LIGIKAUDNE EFEKTIIVNE SUNTEES JA LIBISEV PLANEERIMINE}

Von Neumann - Gale'i tüüpi majandusliku dünaamika mudelis, mis sisaldab muutuvaid tehnoloogilisi hulki, on vaadeldud dünaamilist iteratiivset protseduuri, mida nimetatakse libisevaks planeerimiseks. On tõestatud, et selle abil konstrueeritud trajektoor aproksimeerib etteantud täpsusega lõpmatu optimaalse trajektoori.

\section{M. КАГАНОВИЧ}

\section{ПРИБЛИЖЕННЫИ ЭФФЕКТИВНЫИ СИНТЕЗ И СКОЛЬЗЯЩЕЕ ПЛАНИРОВАНИЕ}

В модели экономической динамики типа Неймана-Гейла с меняющимися во времеш технологическими множествами рассматривается бесконечношаговая итеративная процедура, называемая скользящим планированием, каждый шаг которой является начальным шагом некоторой конечной оптимальной траектории фиксированной длины, рассчитываемой в текущий момент времени. Доказывается, что получаемая с помоњью этой процедуры траектория аппроксимирует с заданной точностью бесконечную оптимальную. Тем самым процедура скользящего планирования является приближенным синтезом бесконечной оптимальной траектории. 